\title{
Thermoadaptation of $\alpha$-Galactosidase AgaB1 in Thermus thermophilus
}

\author{
Olafur Fridjonsson, ${ }^{*}$ Hildegard Watzlawick, and Ralf Mattes \\ Institut für Industrielle Genetik, Universität Stuttgart, 70569 Stuttgart, Germany
}

Received 17 December 2001/Accepted 15 March 2002

\begin{abstract}
The evolutionary potential of a thermostable $\alpha$-galactosidase, with regard to improved catalytic activity at high temperatures, was investigated by employing an in vivo selection system based on thermophilic bacteria. For this purpose, hybrid $\alpha$-galactosidase genes of agaA and agaB from Bacillus stearothermophilus KVE39, designated $a g a A 1$ and $a g a B 1$, were cloned into an autonomously replicating Thermus vector and introduced into Thermus thermophilus OF1053GD ( $\triangle$ agaT) by transformation. This selector strain is unable to metabolize melibiose ( $\alpha$-galactoside) without recombinant $\alpha$-galactosidases, because the native $\alpha$-galactosidase gene, agaT, has been deleted. Growth conditions were established under which the strain was able to utilize melibiose as a single carbohydrate source when harboring a plasmid-encoded agaA1 gene but unable when harboring a plasmid-encoded agaB1 gene. With incubation of the agaB1 plasmid-harboring strain under selective pressure at a restrictive temperature $\left(67^{\circ} \mathrm{C}\right)$ in a minimal melibiose medium, spontaneous mutants as well as $N$-methyl$N^{\prime}$-nitro- $N$-nitrosoguanidine-induced mutants able to grow on the selective medium were isolated. The mutant $\alpha$-galactosidase genes were amplified by PCR, cloned in Escherichia coli, and sequenced. A single-base substitution that replaces glutamic acid residue 355 with glycine or valine was found in the mutant agaB1 genes. The mutant enzymes displayed the optimum hydrolyzing activity at higher temperatures together with improved catalytic capacity compared to the wild-type enzyme and furthermore showed an enhanced thermal stability. To our knowledge, this is the first report of an in vivo evolution of glycoside-hydrolyzing enzyme and selection within a thermophilic host cell.
\end{abstract}

Stability of enzymes and activity at high temperatures are important and desirable properties for various biotechnological processes. Hence, improving stability and activity of enzymes has been the major aim of many applied studies. Thereby, randomization methods for in vitro protein evolution, such as random mutagenesis for obtaining point mutations, DNA shuffling, and elongation mutagenesis, have been successfully applied $(12,18,23,24)$. Another approach for enhancing enzyme properties is to use in vivo evolution systems. Thermostable enzyme variants may be established by cloning mesophilic genes into a thermophilic organism and applying a growth selection where elevated temperatures function as a selective pressure. Such a thermoadaptation was applied, e.g., by the stabilization of kanamycin nucleotidyltransferase in $\mathrm{Ba}$ cillus stearothermophilus $(17,22)$ and by the stabilization of a 3-isopropylmalate dehydrogenase (of the leucine biosynthetic pathway) in Thermus thermophilus (29). Thermoadaptation can also be supported by in vitro mutagenesis followed by a growth selection in a thermophile as described by Kotsuka et al. (13) for the further stabilization of 3-isopropylmalate dehydrogenase in $T$. thermophilus.

Thermoadaptation of proteins may also involve an improvement of properties such as substrate affinities of enzymes at high temperatures. We have studied thermostable $\alpha$-galactosidases from various mesophilic and thermophilic bacteria, including the isoenzymes AgaA and AgaB from Bacillus stearothermophilus $\operatorname{KVE} 39(7,9,11,32)$. Although the amino acid sequences of AgaA and AgaB are highly similar (97\% identity), the enzymes exhibit different properties (11). AgaA dis-

* Corresponding author. Present address: Prokaria Ltd., Gylfaflöt 5, 112 Reykjavik, Iceland. Phone: (354) 570 7914. Fax: (354) 5707901. E-mail: olafur@prokaria.com. plays a high affinity for oligosaccharides such as melibiose and raffinose and a temperature optimum of activity at 65 to $67^{\circ} \mathrm{C}$ under given assay conditions. On the other hand, AgaB displays a low affinity for melibiose and raffinose and a temperature optimum of activity at 45 to $50^{\circ} \mathrm{C}$. Yet $\mathrm{AgaB}$ shows a marginal stability at 60 to $65^{\circ} \mathrm{C}(11,32)$. In a previous work on AgaA and $\mathrm{AgaB}$, it was demonstrated that a central BsmI$H i n$ dIII fragment in their encoding genes, designated aga $A$ and $a g a B$, respectively, could account for the characteristic phenotypes of the enzymes, i.e., the temperature optimum of activity and the hydrolyzing rate $(11,32 ; \mathrm{H}$. Watzlawick, unpublished results). The aim of this work was to establish a selection system for $\alpha$-galactosidases based on a growth selection of thermophilic bacteria, thereby achieving high enzyme activity and stability at elevated temperatures. The fact that the phenotypes of AgaA and AgaB are encoded in genetically exchangeable elements allowed hereby the application of the hybrid genes agaA1 and agaB1 as test genes for the selection system. The hybrid genes differed only in respect to their central BsmI-HindIII fragment (Fig. 1). This simplified plasmid construction protocols; besides, mutations leading to the AgaA phenotype from the AgaB phenotype were expected to take place in this central fragment.

Expression of heterologous genes and a subsequent thermoadaptation of the gene products require the inactivation of analogous genes in the selector strain. A suitable host strain for a selection of thermostable $\alpha$-galactosidases active at elevated temperatures was constructed by applying integration mutagenesis in combination with phenotypic selection and designated T. thermophilus OF1053GD, as previously described (8).

In this paper we describe the cloning of the $\alpha$-galactosidase gene derived from $B$. stearothermophilus in the thermophilic bacterium T. thermophilus and a subsequent selection of en- 


\begin{tabular}{|c|c|c|c|c|}
\hline Bsml (967) & HindIIII (1165) & Enzyme & $\begin{array}{l}\text { Temperature } \\
\text { Optimum }\end{array}$ & $\begin{array}{l}\text { Raffinose } \\
\text { Hydrolysis }\end{array}$ \\
\hline & & AgaA & $67^{\circ} \mathrm{C}$ & Fast \\
\hline \multirow[t]{2}{*}{ Bsml } & HindllI & & & \\
\hline & & AgaB & $50^{\circ} \mathrm{C}$ & Slow \\
\hline \multirow[t]{2}{*}{ Bsml } & HindIIII & & & \\
\hline & & AgaA1 & $67^{\circ} \mathrm{C}$ & Fast \\
\hline Bsml & HindIII & & & \\
\hline & & AgaB1 & $50^{\circ} \mathrm{C}$ & Slow \\
\hline
\end{tabular}

FIG. 1. The phenotypic characteristics of the isoenzymes AgaA and AgaB and their hybrid enzymes, AgaA1 and AgaB1. The corresponding gene structures are shown on the left. The locations of the Bsm I and the HindIII restriction sites in $a g a A$ are indicated with nucleotide numbers.

zyme variants, with an increased temperature optimum of activity and enhanced stability, following adaptation (isolation of spontaneous mutants) or in vitro mutagenesis.

\section{MATERIALS AND METHODS}

Bacterial strains, growth conditions, and transformation procedure. Thermus thermophilus OF1053GD (8) ( $\Delta$ agaT $\Delta$ kan $\mathrm{Gal}^{+}$), a mutant of strain TH125 (10), was used as a host strain for the cloning and the selection procedure. The strain was grown under strong aeration in mineral medium 162 (4) with $0.25 \%$ tryptone and $0.25 \%$ yeast extract at $\mathrm{pH} 7.5$ (T162). Growth was carried out at $65^{\circ} \mathrm{C}$ under nonselective conditions and at $60^{\circ} \mathrm{C}$ when cultures contained kanamycin $(20 \mu \mathrm{g}$ $\mathrm{ml}^{-1}$ ) for plasmid selection. Growth on a single carbon source (melibiose, 0.1, 0.2 , and $0.4 \%$ ) was tested on agar plates containing the minimal medium 162 (4) with a slight modification as previously described (8). The method of Koyama et al. (14) was used for the transformation of T. thermophilus, with a slight modification as previously described (7). Transformants were selected on T162 agar plates containing $20 \mu \mathrm{g}$ of kanamycin $\mathrm{ml}^{-1}$ and incubated at $60^{\circ} \mathrm{C}$ for $48 \mathrm{~h}$. All plasmids constructed, except those which could replicate only in Thermus bacteria, were brought into Escherichia coli JM109 [supE44 $\Delta$ (lac-proAB) hsdR17 recA1 endA1 gyrA96 thi-1 relA1] (F'traD36 proAB lacI $\left.{ }^{\mathrm{q}} \mathrm{Z} \mathrm{M} 15\right)$ (31) by transformation (2). Transformants were either selected for ampicillin resistance on agar plates with $100 \mu \mathrm{g}$ of ampicillin per $\mathrm{ml}$ or for kanamycin resistance on plates with $25 \mu \mathrm{g}$ of kanamycin per ml.

DNA manipulation and general plasmid construction. Recombinant DNA techniques, i.e., plasmid preparation, subcloning, and agarose gel electrophoresis, were performed by conventional protocols (25). Structures of the plasmids were confirmed by restriction mapping. Further, the inserts of pOF 287 and pOF288 were confirmed by sequencing. Sequencing reactions of double-stranded DNA were carried out according to the dideoxy chain termination method with universal and internal primers (26). The plasmids used in this study are listed in Table 1.

Construction of Thermus replication plasmids containing aga $A$ and agaB hybrid genes. Hybrid genes, based on aga $A$ and $a g a B$, of $B$. stearothermophilus KVE39 were cloned into a Thermus autonomously replicating plasmid, downstream of the E. coli tac promoter (1) and a ribosome binding site from $T$. thermophilus (8). The construction of plasmid pOF2811, carrying an AgaA type encoding gene, agaA1, which served as a positive control, was as follows. Plasmid pOF1253 contains agaA1 downstream of the Thermus ribosome binding site. It was constructed by replacing the kan gene of pOF1155 (8), which contains the marker between flanking sequences of the native $\alpha$-galactosidase gene agaT (7), with agaA1. Due to an $N d e$ I restriction site in $\operatorname{agaA}$, a three-fragment ligation was performed with the following: the $a g a A$ gene following amplification (8) and $N d e$ I-HindIII digestion; agaB, following amplification (8) and HindIII-BglII digestion; and the pOF1155 following NdeI-BamHI digestion. The resulting chimeric gene encoded an enzyme with the characteristic phenotypes of AgaA. The construction of pOF10726 is described elsewhere (8). The plasmid contains a stable plasmid mutant of pOF5714 (8) in a pUC19 derivative. A PstI fragment from pOF10726 containing repA, the minimal replication unit (3) from the Thermus plasmid pTSP1 (16), was cloned in pIC20R (19) to produce pOF184. agaA1 along with the Thermus putative Shine-Dalgarno (SD) sequence from pOF1253 was amplified by PCR with primers S1065 and S952 (8). The EcoRI restriction site in the S1065 primer sequence was disrupted by EcoRI digestion and a Klenow modification. This was done in order to be able to use other EcoRI restriction sites in later steps. Subsequently, the gene was blunt end ligated downstream of the tac promoter in pBTac1 (1) to produce pOF182. Further, agaA1 along with the tac promoter and the putative Thermus SD sequence was amplified from pOF182 by PCR with primers S1318 and S952 (8) and cloned between the HindIII and $B g l \mathrm{II}$ sites of pOF184. This was carried out in two steps. First, the $3^{\prime}$ region of agaA1 (a HindIII-BglII fragment) was ligated between the HindIII and BglII sites of pOF184 to produce pOF185. Then, the $5^{\prime}$ region of agaA1, along with the upstream $\mathrm{P}_{t a c}$ sequence, was ligated into the HindIII site of pOF185 to produce pOF187. The kan gene (21), along with the Thermus slpA promoter (16) from pOF1056 (8), was ligated into the MunI site of pOF187 to produce pOF287. The pIC region of pOF287 was deleted by EcoRI digestion, and the remaining plasmid was self-ligated to produce pOF2811 before transformation of $T$. thermophilus. The corresponding AgaB type plasmid, pOF2812, was generated in the same way except the plasmid pOF762 was the initial source of agaB1. To construct pOF762, a BsmI-MunI fragment of pOF1253 was replaced by a corresponding agaB Bsm I-MunI fragment following the amplification of $a g a B$ from pCG3 (11), using the primers S951 and S952 (8) and a BsmI-MunI digestion and a ligation. All plasmids involved in the construction of pOF2811 and pOF2812 are listed in Table 1. Figure 2 shows the last step in the construction of pOF2812 containing agaB1, which was used to transform T. thermophilus OF1053GD for subsequent thermoadaptation experiments.

Thermoadaptation in aqueous culture, $N$-methyl- $N^{\prime}$-nitro- $N$-nitrosoguanidine (MNNG) plasmid mutagenesis, and recloning into $E$. coli. Cells from a lateexponential-phase culture of T. thermophilus OF1053GD carrying pO2812 (with agaB1) were washed in $0.9 \% \mathrm{NaCl}$ and suspended in 162 minimal medium containing $0.4 \%$ melibiose. The cells were incubated at $67^{\circ} \mathrm{C}$ under aeration. Following incubation for 6 days, the cells were diluted (three times) in a fresh medium. Following incubation for 13 days, the culture was diluted and plated on a minimal melibiose agar medium.

Plasmid mutagenesis was performed by adding MNNG to an exponential culture (optical density at $600 \mathrm{~nm}, 0.4$ ) of T. thermophilus OF1053GD harboring pOF2812, in T162 kanamycin medium. Several concentrations of MNNG were tested $\left(0.05\right.$ to $\left.0.250 \mathrm{mg} \mathrm{ml}^{-1}\right)$. Following growth overnight at $60^{\circ} \mathrm{C}$, the cells were washed in $0.9 \% \mathrm{NaCl}$ and plated on 162 minimal melibiose agar medium. Plasmids from strains, capable of growth, were isolated by alkali lysis (25) and reintroduced into a plasmid-free strain of OF1053GD by transformation for the confirmation of the plasmid-dependent phenotype. Further, the mutant genes were amplified by PCR, with primer S462, CGG AAT TCA GAG AAT GTC AGT TGC ATA C, containing an EcoRI linker and S952, GAA GAT CTC AAT

TABLE 1. Plasmids used in this study

\begin{tabular}{|c|c|c|}
\hline Plasmid & Description & Reference \\
\hline pIC20R & $\mathrm{Ap}^{\mathrm{r}}, \mathrm{pBR} 322$ ori $l a c Z$ & 19 \\
\hline pCG1 & $\operatorname{aga} A$ in $\mathrm{pUC} 12$ & 11 \\
\hline pCG3 & agaB in $\mathrm{pUC12}$ & 11 \\
\hline pOF1056 & $\mathrm{P}_{\text {slpA }}-k a n$ from $\mathrm{pMY} 1$ in $\mathrm{pJOE930}$ & 8 \\
\hline pOF5714M & $\begin{array}{l}\text { agaA downstream of the } \mathrm{P}_{\text {slpA }} \text { in Thermus } \\
\text { replication plasmid }\end{array}$ & 8 \\
\hline pOF1176 & $\begin{array}{l}\text { agaB2 downstream of the } \mathrm{P}_{s l p A} \text { in Thermus } \\
\text { replication plasmid }\end{array}$ & 8 \\
\hline pOF10726 & pOF5714M cloned into a pUC derivative & 8 \\
\hline pOF1155 & $\begin{array}{l}\text { kan downstream of the } 5^{\prime} \text { flanking sequence } \\
\text { of agaT from } T \text {. thermophilus in a pUC } \\
\text { derivative }\end{array}$ & 8 \\
\hline pOF1253 & agaA1 in place of kan in pOF1155 & This study \\
\hline pOF762 & agaB1 in place of agaA1 in pOF1253 & This study \\
\hline pOF182 & $\begin{array}{l}\text { agaA1 with a } T \text {. thermophilus SD sequence } \\
\text { in pBTac1 }\end{array}$ & This study \\
\hline pOF183 & $\begin{array}{l}\text { agaB1 with a } T \text {. thermophilus SD sequence } \\
\text { in pBTac1 }\end{array}$ & This study \\
\hline pOF184 & pTSP1 region of pOF10726 in pIC20R & This study \\
\hline pOF185 & $3^{\prime}$ region of agaA1 in pOF184. & This study \\
\hline pOF187 & $\begin{array}{l}\text { agaA1 downstream of } \mathrm{P}_{t a c} \text { and a } T . \text { ther- } \\
\text { mophilus putative SD sequence in pOF184 }\end{array}$ & This study \\
\hline pOF188 & $\begin{array}{l}\text { agaB1 downstream of } \mathrm{P}_{t a c} \text { and a } T \text {. ther- } \\
\text { mophilus putative SD sequence in pOF184 }\end{array}$ & This study \\
\hline pOF287 & $\mathrm{P}_{\text {slpA }}$-kan module from pOF1056 in pOF187 & This study \\
\hline pOF288 & $\mathrm{P}_{\text {slpA }}-$ kan module from pOF1056 in pOF188 & This study \\
\hline pOF2811 & pIC region deleted from pOF287 (agaA1) & This study \\
\hline pOF2812 & pIC region deleted from pOF288 (agaB1) & This study \\
\hline
\end{tabular}




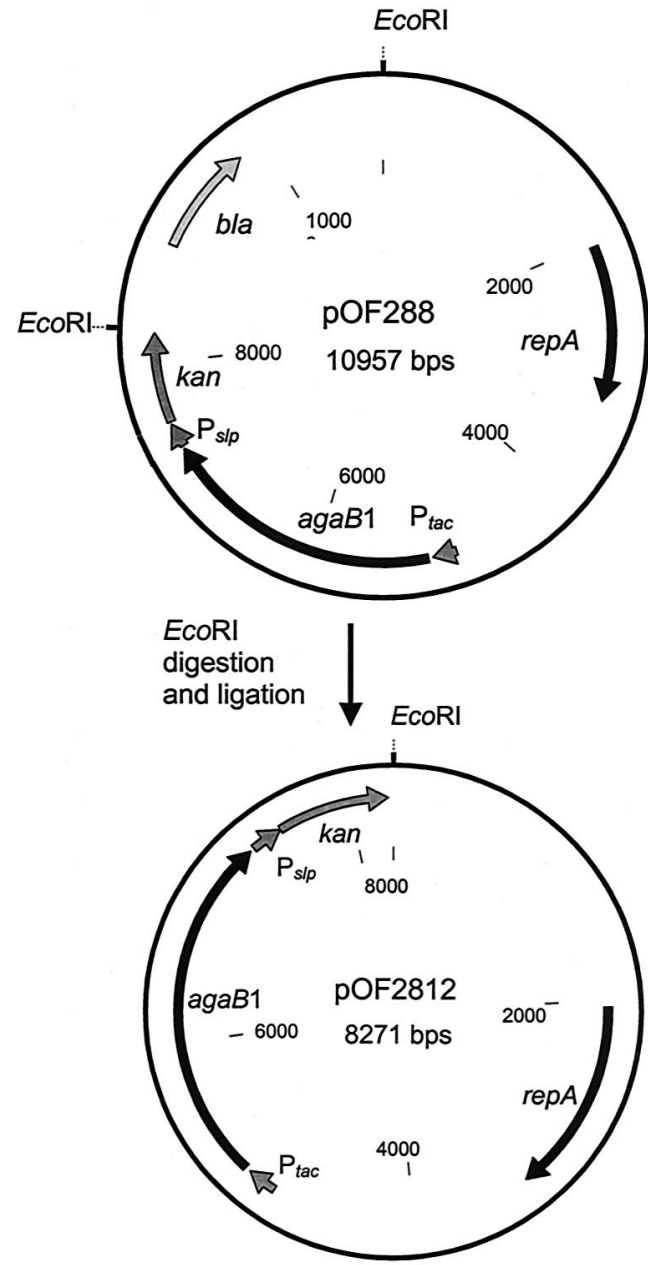

FIG. 2. The last step in the construction of the T. thermophilus plasmid pOF2812, containing agaB1. The progenitor plasmid pOF288 (shuttle vector) was established in E. coli as described in Materials and Methods. Deletion of the pIC region in pOF288 to produce pOF2812 before transformation of $T$. thermophilus was supposed to improve plasmid stability in strain OF1053GD, according to previous results (8).

TGT CTT ATT GTT GAA CAG, containing a BglII linker (8). The amplified fragments were digested with $E c o$ RI and $B g l I I$ and ligated between the EcoRI and Bam HI sites in pBTac1 (1) for the expression and characterization of mutant enzymes and in pUC18 (31) for sequencing.

Enzyme assays. Preparation of crude extracts, estimation of protein concentrations, and procedure of enzyme assays have been described previously (7). $\alpha$-Galactosidase activity was determined by measuring the rate of para-nitrophenyl- $\alpha$-D-galactoside (pNP- $\alpha$-galactoside) hydrolysis $\left(4 \mathrm{mg} \mathrm{ml}^{-1}\right.$ in $0.1 \mathrm{M}$ potassium buffer [ $\mathrm{pH} 6.5])$ at the desired temperature. One unit of activity is defined as the amount of enzyme required to hydrolyze $1 \mu \mathrm{mol}$ of pNP- $\alpha$-galactoside $\min ^{-1}$ under a given assay condition (9). Further, the rate of D-raffinose or melibiose hydrolysis, in $0.1 \mathrm{M}$ potassium buffer, $\mathrm{pH} 6.5$, was determined by assessing the amount of D-galactose released using high performance liquid chromatography equipment (7). Colonies, which displayed $\alpha$-galactosidase activity, were detected by histochemical staining as previously described (8).

Determination of temperature optimum and stability. Production of enzymes for characterization was achieved with $E$. coli JM109 by using the pBTac1 expression vector. The presence of equal amounts of enzymes in crude extracts was verified on a sodium dodecyl sulfate-polyacrylamide gel (15) (data not shown). The temperature optimum was determined by performing pNP- $\alpha$-galactoside assays at a temperature range of 25 to $75^{\circ} \mathrm{C}$. Thermal stability was determined by estimating the $\mathrm{T}[1 / 2]$ value (the temperature at which $50 \%$ enzyme activity is measured after $30 \mathrm{~min}$ of incubation) as follows. The $\alpha$-galacto- sidase variants were partially purified by thermal precipitation of $E$. coli crude extracts $\left(1 \mathrm{mg}\right.$ of protein $\left.\mathrm{ml}^{-1}\right)$ at $60^{\circ} \mathrm{C}$ for $20 \mathrm{~min}$. The enzymes were then incubated in $0.1 \mathrm{M}$ potassium phosphate buffer $(\mathrm{pH}$ 6.5) for $30 \mathrm{~min}$ at various temperatures over a range from 25 to $80^{\circ} \mathrm{C}$. Following incubation the enzyme was cooled, and the remaining activity was determined at the same temperature for all enzymes $\left(37^{\circ} \mathrm{C}\right)$.

Nucleotide sequence accession numbers. The GenBank accession numbers of the nucleotide sequences of agaA and $a g a B$ are AY013286 and AY013287, respectively.

\section{RESULTS AND DISCUSSION}

Establishing a selection system. Our intention was to subject AgaB1 to thermoadaptation for selection of enzyme variants, which supported growth of the host strain on minimal melibiose medium at $67^{\circ} \mathrm{C}$. For the establishment of a selection system, we intended to use AgaA1 as a positive control. In our previous work (8), we inserted the $\alpha$-galactosidase genes aga $\mathrm{A}$ and $a g a B$ into a Thermus autonomously replicating vector downstream of the strong $\operatorname{slp} A$ promoter (16). Cells carrying these plasmids displayed a high-level production of $\alpha$-galactosidases, verified by sodium dodecyl sulfate gel electrophoresis and activity tests (8). Although cells harboring the aga $\mathrm{A}$ plasmid (pOF5714) grew at $67^{\circ} \mathrm{C}$ on agar plates containing minimal melibiose medium, a noncontinuous growth in minimal melibiose aqueous medium was observed (data not shown). This was interpreted as an effect of the high-level $\alpha$-galactosidase gene expression. In our previous work, we observed that a $\mathrm{Gal}^{+}$phenotype of $T$. thermophilus was essential for growth on melibiose (8). As the host strain OF1053GD was capable of growing only slowly on a minimal agar medium containing $0.3 \%$ galactose, it is possible that the galactose metabolism could not fully compensate for the large amount of galactose produced from the melibiose hydrolysis in the cell, due to the high production of AgaA. Therefore, the $\alpha$-galactosidase production was confined by constructing new plasmids with $\alpha$-galactosidase genes inserted downstream of a Thermus ribosome binding site and the E. coli tac promoter, which was known to show low activities in T. thermophilus (20). Concomitantly, the kanamycin selection marker (21) was inserted downstream of the $\operatorname{sip} A$ promoter as in the shuttle vector pMY1 (16). To facilitate the construction of the plasmid modules, hybrid genes of $a g a A$ and $a g a B$, designated $a g a A 1$ and $a g a B 1$, respectively, were used. The enzyme activities in crude extracts of $T$. thermophilus OF1053GD harboring pOF2811 with agaA1 or pOF2812 with agaB1 are shown in Table 2. For the comparison, enzyme activities in T. thermophilus OF1053GD harboring pOF5714 (agaA) and pOF1176 (agaB2) from our previous

TABLE 2. Specific $\alpha$-galactosidase activity $\left(\mathrm{U} \mathrm{mg}^{-1}\right)$ in crude extracts of T. thermophilus OF1053GD harboring different $\alpha$-galactosidase plasmids

\begin{tabular}{ccccc}
\hline & \multicolumn{4}{c}{ Sp act $\left(\mathrm{U} \mathrm{mg}^{-1}\right)^{a}$} \\
\cline { 2 - 5 } Temp $\left({ }^{\circ} \mathrm{C}\right)$ & $\begin{array}{c}\mathrm{pOF} 2811 \\
(\text { AgaA1) }\end{array}$ & $\begin{array}{c}\text { pOF2812 } \\
(\text { AgaB1) }\end{array}$ & $\begin{array}{c}\text { pOF5714M } \\
(\text { AgaA })\end{array}$ & $\begin{array}{c}\text { pOF1176 } \\
(\text { AgaB2) }\end{array}$ \\
\hline $50^{a}$ & 1.1 & 3.4 & 12.1 & 46.8 \\
$60^{a}$ & 2.2 & 2.2 & 23.4 & 30.6 \\
\hline
\end{tabular}

${ }^{a}$ Activity tests (in triplicates) were performed using pNP- $\alpha$-galactopyranoside as substrate. The maximum variation from the mean values (shown) was less than $5 \%$.

${ }^{5 \%}$ For more details about pOF5714M and pOF1176, see reference 7. 


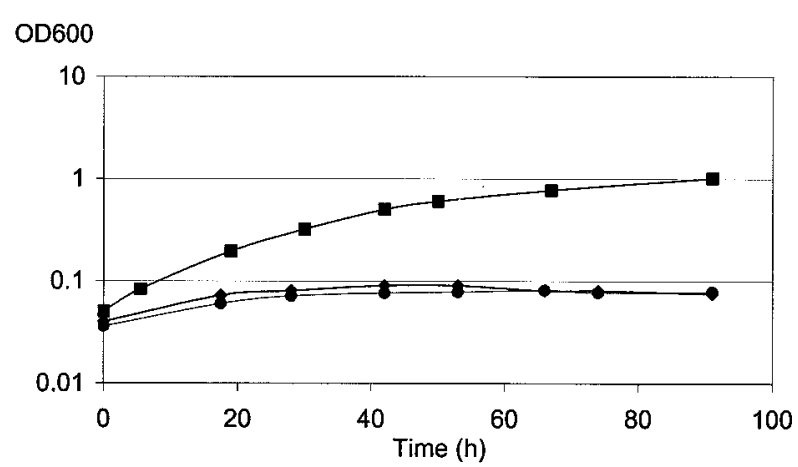

FIG. 3. Growth of T. thermophilus $\mathrm{OF} 1053 \mathrm{GD}$ at $67^{\circ} \mathrm{C}$, in minimal medium containing $0.4 \%$ melibiose as a single carbohydrate source. $\mathbf{\square}$, OF1053GD/pOF2811 (agaA1); •, OF1053GD/pOF2812 (agaB1); OF1053GD without plasmid.

work (8), with the $\alpha$-galactosidase genes downstream of the $\operatorname{slp} A$ promoter (16), are shown. Purified AgaA and AgaB2 displayed specific activities similar to those of AgaA1 and AgaB1, respectively (data not shown). As expected, a roughly 10 -fold lower level of enzyme activity was measured in cells containing the $\alpha$-galactosidase genes downstream of the tac promoter. Moreover, the strain OF1053GD harboring the agaA1 plasmid pOF2811 exhibited stable growth in a liquid minimal melibiose medium $(0.4 \%)$. In contrast, OF1053GD without a plasmid or harboring the agaB1 gene in the plasmid pOF2812 remained in the lag phase for a period of days (Fig. 3 ). Also, growth at $67^{\circ} \mathrm{C}$ on minimal agar plates containing 0.2 and $0.1 \%$ melibiose was observed only with strain OF1053GD carrying the agaA1 gene in plasmid pOF2811 (Table 3) following incubation for 5 days. Thus, the requirements for the genetic selection were achieved.

Thermoadaptation of AgaB1, MNNG mutagenesis, and screening. T. thermophilus OF1053GD harboring pOF2812 (agaB1) was incubated at $67^{\circ} \mathrm{C}$ in an aqueous minimal medium containing $0.4 \%$ melibiose. The cells divided once and then remained in the lag phase. Although the cells did not grow at this temperature during the first days, no death phase was observed, according to cell titer quantification (data not shown). Slow growth was observed after 11 days of incubation. The cells were plated out and tested for growth on minimal agar medium. A thermoadapted strain harboring a plasmid, designated pOF2812 M1, was selected for further examination. Subsequently, the plasmid was isolated from its host strain and reintroduced into a plasmid-free strain of OF1053GD.

Another approach for selecting thermoadapted mutants involved reinforcement with mutagens. Following treatment with MNNG, as explained in Materials and Methods, mutants were plated and screened on a minimal agar medium containing $0.2 \%$ melibiose. Plasmid mutagenesis is commonly applied by adding the mutagenic agent to the culture medium (28). The highest number of mutants was obtained with a relatively high dose $\left(0.15 \mathrm{mg} \mathrm{ml}^{-1}\right)$, probably due to instability of MNNG in rich medium and at high temperatures. Four independent mutants, capable of growth, were isolated following incubation at the restricted temperature of $67^{\circ} \mathrm{C}$ for 6 days. The corresponding plasmids, designated pOF2812 M2 to M5, were isolated from their host strain and reintroduced into a plasmid-free strain of OF1053GD. The cells carrying these different plas- mids, including pOF2812 M1, with the spontaneous mutation, were all capable of growing at $67^{\circ} \mathrm{C}$ on a minimal melibiose medium, thus confirming the plasmid-dependent phenotype. Further, $\alpha$-galactosidase activity at 50 and $60^{\circ} \mathrm{C}$ in crude extracts of the plasmid-harboring strains was examined. All enzymes displayed higher activity at 60 than at $50^{\circ} \mathrm{C}$, in contrast to the wild-type enzyme AgaB1.

Sequencing and characterization of the mutant enzymes. The sequencing of the mutant genes, designated agaM1 to agaM5 (from pOF2812 M1 to M5, respectively), revealed a single nucleotide replacement in all cases. In agaM1 to agaM4, A-1064, according to agaB1 signature, was replaced with G. This mutation is located, as expected, in the BsmI-HindIII fragment of the gene and corresponds to a Glu355 $\rightarrow$ Gly amino acid replacement. In agaM5, the same nucleotide (A-1064) was replaced with $\mathrm{T}$, which corresponds to a Glu355 $\rightarrow$ Val amino acid replacement. These base substitutions are inconsistent with the generally accepted effect of MNNG mutagenesis, which most commonly leads to $\mathrm{GC} \rightarrow$ AT transitions (27). Nevertheless, control plating indicated the mutagenic effect of MNNG. No colonies were detected during the mutagen approach, on minimal agar medium following 6 days of incubation, where cells without a mutagenic treatment had been plated as a control. On the other hand, the A1064 $\rightarrow$ G transition in pOF2812 M1, which occurred spontaneously, was detected following a prolonged incubation at a restricted temperature. Although MNNG-induced $A \rightarrow G$ transitions or $\mathrm{A} \rightarrow \mathrm{T}$ transversions are generally infrequent, such mutations induced with alkylating agents are common in E. coli alkA mutants, which are deficient for 3-methyladenine DNA glycosylase II, involved in induced DNA repair activities. In most cases these mutations are $u m u C^{+}$dependent, i.e., resulting from SOS mutagenic processing (6). Thus, it is possible that deficient specific DNA repair activities in T. thermophilus OF1053GD, induced by exposure of MNNG, caused the base substitutions at A/T site 1064 to occur. Also, this site may be a substitution hot spot, similar to what is known to occur in $E$. coli (5).

The enzymatic properties of AgaM4 (Glu $\rightarrow$ Gly) and AgaM5 $(\mathrm{Glu} \rightarrow \mathrm{Val})$ were examined and compared with those of the wild-type enzyme (AgaB1). Figure 4 shows the effect of temperature on the activity and stability (panels A and B, respectively). The optimum hydrolyzing activity of AgaM4 (following $15 \mathrm{~min}$ of preincubation at respective temperatures) was determined to be at $65^{\circ} \mathrm{C}$, about $15^{\circ} \mathrm{C}$ higher than for the wildtype enzyme $\left(50^{\circ} \mathrm{C}\right)$. The optimum activity of AgaM5 was determined to be at $60^{\circ} \mathrm{C}$ (Fig. 4A). The temperature where $50 \%$

TABLE 3. Growth of T. thermophilus OF1053GD harboring $\alpha$-galactosidase-plasmids on minimal agar medium containing different concentration of melibiose ${ }^{a}$

\begin{tabular}{|c|c|c|c|c|c|c|}
\hline \multirow[t]{2}{*}{ Plasmid } & \multicolumn{3}{|c|}{$\begin{array}{l}\text { Growth at } 60^{\circ} \mathrm{C} \\
\text { with Melibiose } \\
\text { concn }(\%) \text { of: }\end{array}$} & \multicolumn{3}{|c|}{$\begin{array}{l}\text { Growth at } 67^{\circ} \mathrm{C} \\
\text { with Melibiose } \\
\text { concn }(\%) \text { of: }\end{array}$} \\
\hline & 0.4 & 0.2 & 0.1 & 0.4 & 0.2 & 0.1 \\
\hline $\begin{array}{l}\text { pOF2811 }(\text { agaA1) } \\
\text { pOF2812 }(\text { agaB1) }\end{array}$ & $\begin{array}{l}+++ \\
+++\end{array}$ & $\begin{array}{l}+++ \\
++\end{array}$ & $\begin{array}{l}+++ \\
+\end{array}$ & $\begin{array}{l}+++ \\
+\end{array}$ & $\begin{array}{l}+++ \\
-\end{array}$ & $\begin{array}{l}+++ \\
-\end{array}$ \\
\hline
\end{tabular}

${ }^{a}+++$, growth following 3 to 4 days of incubation; ++ , growth following 5 to 6 days of incubation; +, growth following 7 days of incubation; -, no growth. 
A

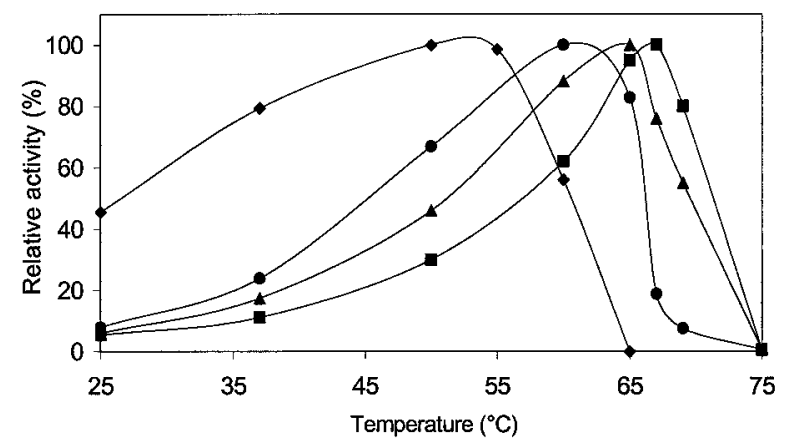

B

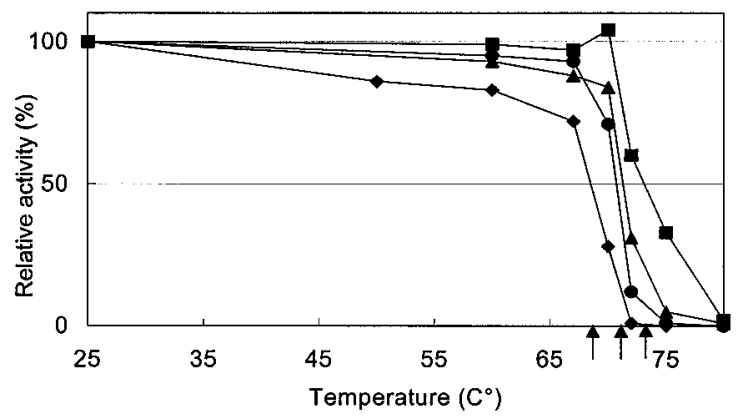

FIG. 4. Effect of temperature on the pNP- $\alpha$-galactopyranoside hydrolyzing activity (A) and stability (B) of AgaA ( $\square)$, AgaB1 ( $)$,

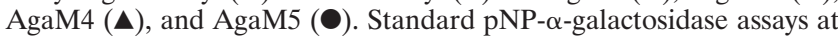
$\mathrm{pH} 6.5$ were performed using enzymes in $E$. coli crude extracts of protein concentration $1 \mathrm{mg} \mathrm{ml}^{-1}$. Temperature stability was determined by measuring the residual $\alpha$-galactosidase activity after incubation of enzymes at a temperature range of 25 to $80^{\circ} \mathrm{C}$ as described in Materials and Methods. T[1/2], the temperature where the remaining activity is $50 \%$ following $30 \mathrm{~min}$ of incubation, is indicated by arrows. All activity tests were done in triplicate. The maximum variation from the mean values (shown) was less than $5 \%$.

of the activity remains following a 30-min incubation (T[1/2]) was determined to be $71^{\circ} \mathrm{C}$ for the mutant enzymes, at least $3^{\circ} \mathrm{C}$ higher than for the AgaB1 enzyme (Fig. 4B). Although this difference is not large, these results were reproducible. The slightly enhanced stability observed for the mutant enzymes can, however, hardly account for the increase in the temperature optimum for the hydrolyzing activity. Table 4 summarizes the $K_{m}$ values of AgaA, AgaB1, AgaM4, and AgaM5 for the hydrolysis of pNP- $\alpha$-galactopyranoside at 25,50 , and $60^{\circ} \mathrm{C}$. The $K_{m}$ of AgaB1 increases substantially along with a rise in temperature, whereas the $K_{m}$ values of the mutant enzymes remain

TABLE 4. $K_{m}$ values for pNP- $\alpha$-galactoside hydrolysis ${ }^{a}$

\begin{tabular}{ccccc}
\hline \multirow{2}{*}{ Temp $\left({ }^{\circ} \mathrm{C}\right)$} & \multicolumn{4}{c}{$K_{m}$ value for: } \\
\cline { 2 - 5 } & AgaA & AgaB1 & AgaM4 & AgaM5 \\
\hline 25 & 0.38 & 0.83 & 0.24 & 0.16 \\
50 & 0.39 & 3.80 & 0.34 & 0.25 \\
60 & 0.40 & 9.5 & 0.43 & 0.26 \\
\hline
\end{tabular}

${ }^{a}$ Activity tests were done in triplicate. The maximum variation from the mean values (shown) was less than $5 \%$.
TABLE 5. Kinetic parameters of $\alpha$-galactosidases ${ }^{a}$

\begin{tabular}{|c|c|c|c|c|c|c|c|}
\hline \multirow{2}{*}{ Enzyme } & \multirow{2}{*}{ AS 355} & \multicolumn{3}{|c|}{ Melibiose } & \multicolumn{3}{|c|}{ Raffinose } \\
\hline & & $\begin{array}{c}K_{m} \\
(\mathrm{mM})\end{array}$ & $\begin{array}{c}V_{\max } \\
\left(\mathrm{U} \mathrm{mg}^{-1}\right)\end{array}$ & $V_{\max } / K_{m}$ & $\begin{array}{c}K_{m} \\
(\mathrm{mM})\end{array}$ & $\begin{array}{c}V_{\max } \\
\left(\mathrm{U} \mathrm{mg}^{-1}\right)\end{array}$ & $V_{\max } / K_{m}$ \\
\hline AgaA & Ala & 3.3 & 45 & 13.6 & 6.7 & 48 & 7.2 \\
\hline AgaB1 & Glu & 133 & 370 & 2.8 & 140 & 120 & 0.9 \\
\hline AgaM4 & Gly & 4.1 & 255 & 63.7 & 13.5 & 270 & 20.0 \\
\hline AgaM5 & Val & 3.2 & 83 & 25.9 & 6.7 & 71 & 10.6 \\
\hline
\end{tabular}

${ }^{a}$ Hydrolyzing reactions were performed at $37^{\circ} \mathrm{C}$ in $0.1 \mathrm{M}$ potassium phosphate buffer ( $\mathrm{pH}$ 6.5). Michaelis-Menten kinetics of hydrolyzing reactions were verified by plotting reaction rates against substrate concentration. The kinetic parameters were determined graphically from Lineweaver-Burk plotting of the initial cleavage rate. Activity tests were done in triplicate. The maximum variation from the mean values (shown) was less than $5 \%$. AS 355 , amino acid residue at position 355 .

below $0.5 \mathrm{mM}$. Thus, the hydrolyzing rate of AgaB1 at high temperatures is affected by the drastic change in substrate affinity. Table 5 summarizes the kinetic parameters of AgaA, AgaB1, and the mutant enzymes for melibiose and raffinose hydrolysis. The $K_{m}$ values for AgaM4 and AgaM5 are much lower than for AgaB1 and resemble the values of AgaA. Further, the mutant enzymes are superior to the progenitor enzyme (AgaB1) in regard to catalytic properties and are even considerably better than AgaA as reflected by the $V_{\text {max }} / K_{m}$ values in Table 5 for hydrolysis at $37^{\circ} \mathrm{C}$.

To verify that the described single-nucleotide replacements at position 355 are determinative for the new enzyme phenotypes, the observed point mutations were introduced into the $a g a B$ gene. This was carried out using our routinely applied $E$. coli expression vector construct ( $a g a B$ in $\mathrm{pBTac} 1$ ) and a conventional site-directed mutagenesis (25). The resulting mutant enzymes were produced, isolated from E. coli, and characterized. The mutants derived thereby were identical to AgaM4 and AgaM5, respectively (data not shown). The results indicate that amino acid residue 355 influences the kinetic properties and stability of the $B$. stearothermophilus $\alpha$-galactosidases. It seems unlikely that the modest increase in thermostability displayed by the mutants (Fig. 4B) is responsible for the dramatic difference in $K_{m}$ values. It seems more likely that the residue at position 355 affects the affinity for the substrate more directly. A simple, plausible explanation may be that the binding or access to the binding site is obstructed by the large side chain of the glutamate residue but not by the smaller side chains of the residues found in AgaA (Ala) and the mutants (Gly and Val). Yet in absence of a three-dimensional structure of the enzyme, this remains speculative. According to the nature of the amino acid residue 355 in AgaA as well as in the thermoadapted mutants, nonpolar side chains or uncharged polar side chains of amino acid 355 may be compulsory for the enzyme to acquire the properties suitable for $\alpha$-galactoside hydrolysis at high temperatures $\left(60\right.$ to $\left.70^{\circ} \mathrm{C}\right)$. Figure 5 shows an amino acid alignment of bacterial $\alpha$-galactosidase partial sequences which correspond to the BsmI-HindIII fragment of $a g a A$ and $a g a B$. All of them contain Ala in position 355 (according to the AgaB1 sequence numbering), except AgaB1 and the $\alpha$-galactosidase from Bacillus halodurans (accession number NP_243089), which contains Gly as observed in AgaM1 to AgaM4. Further analysis of the evolutionary potential of $\alpha$-ga- 

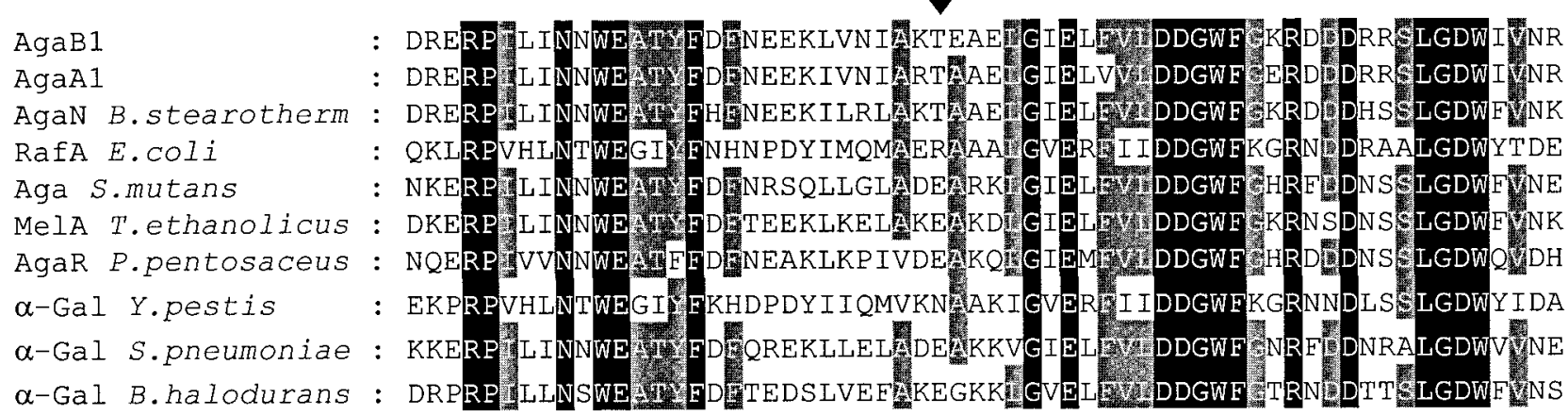

FIG. 5. Alignment of $\alpha$-galactosidase partial amino acid sequences, residues 326 to 387 according to AgaB1 amino acid signature. The sequence region corresponds approximately to the BsmI-HindIII fragment of AgaA and AgaB. Amino acid sequences of bacterial $\alpha$-galactosidases belonging to family 36 and with a subunit size of about $80 \mathrm{kDa}$ (7) were retrieved from protein databases according to their accession numbers and aligned by using CLUSTALX version 1.8 (30). The sequences are as follows: AgaB1, (the sequence region is identical to the corresponding region in AgaB from B. stearothermophilus [B. stearotherm] KVE39, accession no. AY013287); AgaA1 (the sequence region is identical to the corresponding region in AgaA from B. stearothermophilus KVE39, accession no. AY013286); AgaN from B. stearothermophilus NUB3621 (accession no. AF130985); RafA from E. coli, accession no. P16551; Aga from Streptococcus mutans, accession no. P27756; MelA from Thermoanaerobacter ethanolicus, accession no. CAA69852; AgaR from Pediococcus pentosaceus, accession no. L32093; $\alpha$-galactosidase from Yersinia pestis, accession no. NP 405164; $\alpha$-galactosidase from Streptococcus pneumoniae, accession no. NP 346329; $\alpha$-galactosidase from B. halodurans, accession no. NP_243089. Identical residues are indicated with black boxes (shade threshold, $100 \%$ ) and gray boxes (shade threshold, $80 \%$ ). The residue corresponding to amino acid 355 in AgaB1 is marked with a solid triangle.

lactosidases may be attempted, e.g., by applying this system for selection of mutants at temperatures over $70^{\circ} \mathrm{C}$.

Concluding remarks and general discussion. Thermophilic selection systems, such as the one described in this paper, can be useful for isolation of enzyme variants with improved thermostability. Yet, substantial thermostabilization of mesophilic proteins by means of in vitro or in vivo evolution systems may be a difficult task since the routes around multidimensional thermodynamic obstacles to suitable thermostable structures are difficult to find and evolving structures tend to get caught in thermodynamic troughs. Another potential application for thermophilic in vivo evolution systems is to establish thermostable enzyme variants with improved specific activity at elevated temperatures for relevant substrates. In fact, this may be especially pragmatic since thermophilic enzymes sometimes show lower specific activity than their mesophilic or less thermophilic counterparts at their respective temperature optima. We have seen this in the case of $\alpha$-galactosidases where the thermostable $\alpha$-galactosidases from Thermus spp. display, in general, a lower specific activity for some substrates than their less thermostable counterparts from B. stearothermophilus, E. coli, and Streptococcus mutans at respective temperature optima (7; also unpublished results). Yet do we need a thermophile to promote such mutants; i.e., can an E. coli selection system serve this purpose? We have observed that selection of enzyme variants with improved catalytic activity can be dependent on the growth temperature of the selector organism; e.g., in previous work in this laboratory, an attempt was made to isolate variants of $\mathrm{AgaB}$ with improved catalytic activity by applying mutagenesis, using $E$. coli and selecting for growth at $37^{\circ} \mathrm{C}$. Enzyme variants were isolated which displayed improved catalytic activity, but only at moderate temperatures (37 to $50^{\circ} \mathrm{C}$ ) (A. Gehweiler et al., unpublished results). Mutants with improved catalytic activity at elevated temperatures $\left(>60^{\circ} \mathrm{C}\right)$ were obtained only by applying the thermophilic selection system described in this paper.
Although various $\alpha$-galactosidases of eubacterial and eukaryotic sources have been studied extensively regarding their biochemical and physical properties and a number of sequences are available in databases, the structure and detailed catalytic mechanisms remain to be solved. Hence, for improvement of enzyme properties, rational design and protein engineering by site-directed mutagenesis are restricted. In this study we employed an in vivo system to investigate the evolutionary potential of an $\alpha$-galactosidase. We succeeded in isolating mutants which supported the growth of the thermophilic host cells at an elevated temperature $\left(67^{\circ} \mathrm{C}\right)$ on a selective medium. Characterization of the mutants revealed improved substrate affinity and catalytic capacity at elevated temperatures besides slightly enhanced thermostability. The results show that thermophilic bacteria can principally be applied for a thermoadaptation of glycoside-hydrolyzing enzymes. Thus, such in vivo evolution systems should be applicable to other industrially important enzymes as well, and in combination with in vitro evolution techniques, such as gene shuffling, should present a powerful method for obtaining thermoactive and thermostable enzymes. The prerequisite is the capability of the thermophilic host to import and metabolize the relevant substrates and the evolutionary potential of the particular enzyme.

\section{ACKNOWLEDGMENTS}

We thank Gisela Kwiatkowski for technical assistance and Arnthor Ævarsson for critical reading of the manuscript.

This work was supported by the Bundesministerium für Bildung, Wissenschaft, Forschung und Technologie, Germany.

\section{REFERENCES}

1. Amann, E., J. Brosius, and M. Ptashne. 1983. Vectors bearing a hybrid trp-lac-promoter useful for regulated expression of cloned genes in Escherichia coli. Gene 25:167-178.

2. Chung, C. T., S. L. Niemela, and R. H. Miller. 1989. One-step preparation of competent Escherichia coli: transformation and storage of bacterial cells in the same solution. Proc. Natl. Acad. Sci. USA 86:2172-2175. 
3. de Grado, M., I. Lasa, and J. Berenguer. 1998. Characterization of a plasmid replicative origin from an extreme thermophile. FEMS Microbiol. Lett. 165:51-57.

4. Degryse, E., N. Glansdorff, and A. Piérard. 1978. A comparative analysis of extreme thermophilic bacteria belonging to the genus Thermus. Arch. Microbiol. 117:189-196.

5. Foster, P. L., E. Eisenstadt, and J. Cairns. 1982. Random components in mutagenesis. Nature 299:365-367.

6. Foster, P. L., and E. Eisenstadt. 1985. Induction of transversion mutations in Escherichia coli by $N$-methyl- $N^{\prime}$-nitro- $N$-nitrosoguanidine is SOS dependent. J. Bacteriol. 163:213-220.

7. Fridjonsson, O., H. Watzlawick, A. Gehweiler, T. Rohrhirsch, and R. Mattes. 1999. Cloning of the gene encoding a novel thermostable $\alpha$-galactosidase from Thermus sp. ITI360. Appl. Environ. Microbiol. 65:3955-3964.

8. Fridjonsson, O., and R. Mattes. 2001. Production of recombinant $\alpha$-galactosidase in Thermus thermophilus. Appl. Environ. Microbiol. 67:4192-4198.

9. Ganter, C., A. Böck, P. Buckel, and R. Mattes. 1988. Production of thermostable recombinant $\alpha$-galactosidase suitable for raffinose elimination from sugar beet syrup. J. Biotechnol. 8:301-310.

10. Hidaka, Y., M. Hasegawa, T. Nakahara, and T. Hoshino. 1994. The entire population of Thermus thermophilus cells is always competent at any growth phase. Biosci. Biotech. Biochem. 58:1338-1339.

11. Janz, L., C. Ganter, J. Stezowski, and R. Mattes. 1991. Elucidation of functional domains in thermostable isoenzymes of $\alpha$-galactosidase in Bacillus stearothermophilus. Enzymatic properties are encoded in a genetically exchangeable domain, p. 170-173. In M. Reuss, H. Chmiel, E.-D. Gilles, and H.-J. Knackmuss (ed.), Biochemical engineering. Gustav Fischer, Stuttgart, Germany.

12. Joyet, P., N. Declerck, and C. Gaillardin. 1992. Hyperthermostable variants of a highly thermostable alpha-amylase. Biotechnology 10:1579-1583.

13. Kotsuka, T., S. Akanuma, M. Tomuro, A. Yamagishi, and T. Oshima. 1996. Further stabilization of 3-isopropylmalate dehydrogenase of an extreme thermophile, Thermus thermophilus, by a suppressor mutation method. J. Bacteriol. 178:723-727.

14. Koyama, Y., T. Hoshino, N. Tomizuka, and K. Furukawa. 1986. Genetic transformation of the extreme thermophile Thermus thermophilus and of other Thermus spp. J. Bacteriol. 166:338-340.

15. Laemmli, U. K. 1970. Cleavage of structure proteins during the assembly of the head of bacteriophage T4. Nature 227:680-685.

16. Lasa, I., M. de Grado, M. A. de Pedro, and J. Berenguer. 1992. Development of Thermus-Escherichia shuttle vectors and their use for expression of the Clostridium thermocellum celA gene in Thermus thermophilus. J. Bacteriol. 174:6424-6431.

17. Liao, H., T. McKenzie, and R. Hageman. 1986. Isolation of a thermostable enzyme variant by cloning and selection in a thermophile. Proc. Natl. Acad. Sci. USA 83:576-580.
18. Makino, Y., S. Negoro, and H. Okada. 1989. Stability-increasing mutants of glucose dehydrogenase from Bacillus megaterium IWG3. J. Biol. Chem. 11: 6381-6385

19. Marsh, J. L., M. Erfle, and E. J. Weykes. 1984. The pIC plasmid and phage vectors with versatile cloning sites for recombinant selection by insertional inactivation. Gene 32:481-485.

20. Maseda, H., and T. Hoshino. 1995. Screening and analysis of DNA fragments that show promoter activities in Thermus thermophilus. FEMS Microbiol. Lett. 128:127-134.

21. Matsumura, M., Y. Katakura, T. Imanaka, and S. Aiba. 1984. Enzymatic and nucleotide sequence studies of a kanamycin-inactivation enzyme encoded by a plasmid from thermophilic bacilli in comparison with that encoded by plasmid pUB110. J. Bacteriol. 160:413-420.

22. Matsumura, M., and S. Aiba. 1985. Screening for thermostable mutant of kanamycin nucleotidyltransferase by the use of a transformation system for a thermophile, Bacillus stearothermophilus. J. Biol. Chem. 260:15298-15303.

23. Matsuura, T., K. Miyai, S. Trakulnaleamsai, T. Yomo, Y. Shima, S. Miki, K. Yamamoto, and I. Urabe. 1999. Evolutionary molecular engineering by random elongation mutagenesis. Nat. Biotechnol. 17:58-61.

24. Moore, J. C., and F. H. Arnold. 1996. Directed evolution of para-nitrobenzyl esterase for aqueous-organic solvents. Nat. Biotechnol. 4:458-467.

25. Sambrook, J., E. F. Fritsch, and T. Maniatis. 1989. Molecular cloning: a laboratory manual, 2nd ed. Cold Spring Harbor Laboratory Press, Cold Spring Harbor, N.Y.

26. Sanger, F., S. Nicklen, and A. R. Coulson. 1977. DNA sequencing with chain-terminating inhibitors. Proc. Natl. Acad. Sci. USA 7:5463-5467.

27. Schendel, P. F., and P. E. Robins. 1978. Repair of $O$-methylguanine in adapted Escherichia coli. Proc. Natl. Acad. Sci. USA 75:6017-6020.

28. Talmadge, K., and W. Gilbert. 1980. Construction of plasmid vectors with unique Pst cloning sites in a signal sequence coding region. Gene 12:235241.

29. Tamakoshi, M., A. Yamagishi, and T. Oshima. 1995. Screening of stable proteins in an extreme thermophile Thermus thermophilus. Mol. Microbiol. 16:1031-1036.

30. Thompson, J. D., T. J. Gibson, F. Plewniak, F. Jeanmougin, and D. G. Higgins. 1997. The ClustalX windows interface: flexible strategies for multiple sequence alignment aided by quality analysis tools. Nucleic Acids Res. 24:4876-4882.

31. Vieira, J., and J. Messing. 1982. The pUC plasmids and M13mp7 derived system for insertion mutagenesis and sequencing with synthetic universal primers. Gene 19:259-268.

32. Watzlawick, H., C. Ganter, J. Stezowski, and R. Mattes. 1991. Comparison of $\alpha$-galactosidase genes: homologous domains in thermostable and thermolabile enzymes, p. 174-176. In M. Reuss, H. Chmiel, E.-D. Gilles and H.-J. Knackmuss (ed.), Biochemical engineering. Gustav Fischer, Stuttgart, Germany. 